\title{
Novel Drug Delivery Systems for Modulation of Gastrointestinal Transit Time
}

\author{
Yousef Javadzadeh and Sanaz Hamedeyazdan
}

Additional information is available at the end of the chapter

http://dx.doi.org/10.5772/50250

\section{Introduction}

In view of from recent advancements, in a time of augmented remarks to the efficacy and safety of the medicines embedded in dosage forms, it seems as important as ever to study the pharmaceutical concept of the latter in different aspects, prerequisite for a successful pharmacotherapy.

Despite tremendous advancements in drug delivery, oral administration of therapeutic agents still remains the favored rout for majority of clinical applications, due to the excellent accessibility, and patient compliance as well as the preferred alternative route of drug administration for non-invasive drug delivery among the other various routes [Motlekar \& Youan, 2006]. Although there have been several limitations in oral administration of drugs like non-uniform drug absorption profiles, incomplete drug release, shorter residence time of dosage forms in absorption window and etc. to systemic circulation it has come a long way. Now, it has turned towards modifying and manipulating oral dosage forms to exploit from different conditions of the gastrointestinal (GI) tract for drug delivery in various ways [Hirtz, 1985].

In view of the fact that the correlation between drug intake and a clinical response is complex enough, the choice and design of the ideal pharmaceutical dosage form of a drug delivery system would be critically important to reach a progress in superior drug development. Variations between drug response within individuals could be attributed either to product bioavailability (like the rate and extent of drug absorption), drug pharmacokinetics (which includes the metabolism, distribution, and elimination of a drug), or the particular concentration-effect relationship, which in turn could potentially be influenced through a mixture of intrinsic and extrinsic variables [Hirtz, 1985; Martinez \& Amidon, 2002; Javadzadeh et al., 2010]. 
With reference to the Biopharmaceutical Classification System, introduced by the Food and Drug Administration (FDA) in 1995, drugs have been categorized in terms of their solubility and intestinal permeability in four primary groups (Figure 1).

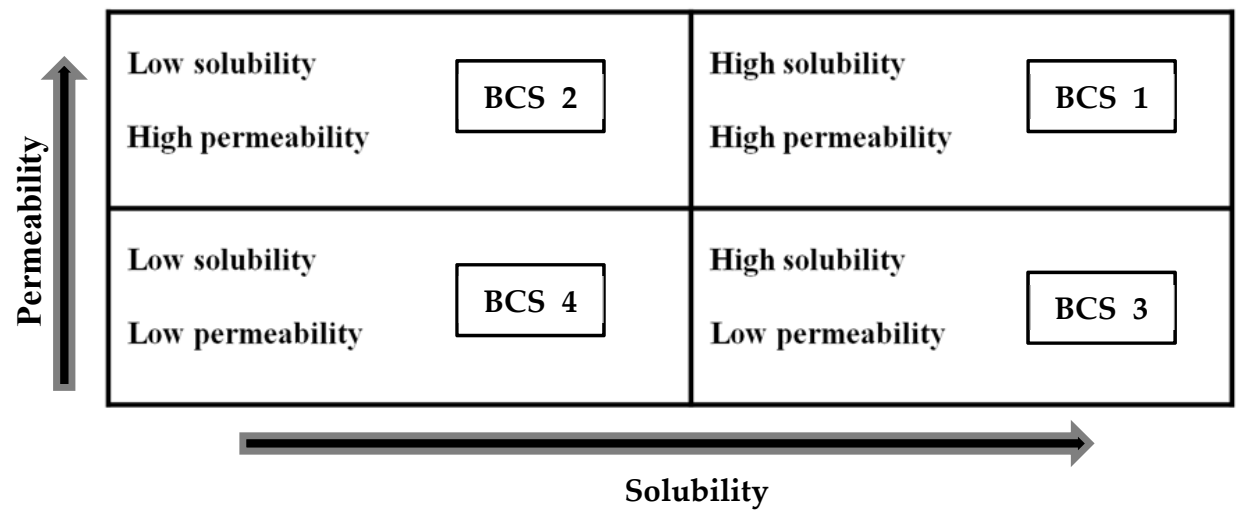

Figure 1. The Biopharmaceutical Classification System (BCS) as defined by the FDA

Drugs that are categorized in class one (BCS 1) are supposed to be well absorbed when taken orally, due to their high solubility and high permeability characteristics. Whereas, all other drugs in BSCs 2 to 4 suffer from low solubility, low permeability or both, and would present challenges to the drug developments. Drugs that are classified in low solubility groups keep drug absorption via the GI tract as the limiting factor for reaching in suitable blood-levels of drugs [Martinez \& Amidon, 2002; Javadzadeh et al., 2007).

As far as we know, absorption of drugs from intake (e.g., oral delivery systems) to its site of action is a complex process, or more accurately, a combination or succession of complicated processes which is schematically presented in Figure 2.

After oral administration, drug leaves the formulation and dissolves in the aqueous digestive fluids. It reacthes and crosses the GI mucosal membrane before passing into blood, moving along the GI tract with the luminal content at a variable speed. Once the drug is reached into the blood circulation, processes of drug metabolism and elimination starts, whilst, it is also possible for some drug degradation or metabolism to occur sooner than the absorption is completed leading for a decrease in drug efficiency [Riley et al., 1992].

In general, absorption of drugs through GI tract varies on account of many factors like the nature and surface area of the GI mucosal membrane varying from the stomach to the rectum, as well as the physicochemical properties of the pharmaceutical dosage form along with the luminal content. Hence, a balance among these factors would have a notable effect on how much of the administered drug reaches to the bloodstream that is summed up by the term bioavailability. Considering the pharmacokinetics and disciplines of drug discovery and drug delivery, it has become obvious that a deep understanding of the biology and anatomy of the GI tract is of substantial value for optimizing the bioavailability of orally administered drugs. 


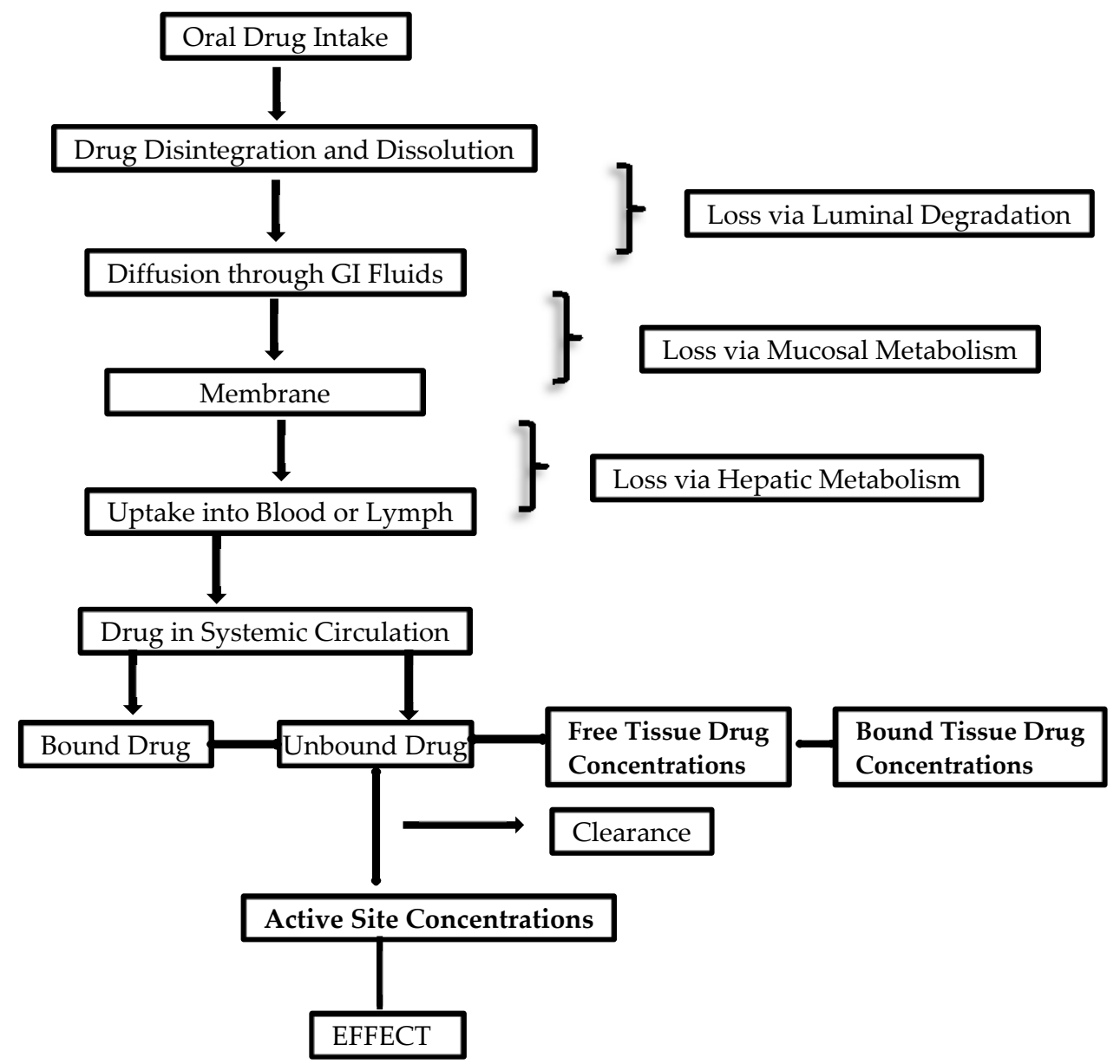

Figure 2. Schematic representation of the relationship between an oral dosage form of a drug and its ultimate effect.

\section{GI anatomy and dynamics}

GI tract is a group of organs joined in a long tube which is divided into several sections, each of that fulfills a specific function. The tract begins with oral cavity, follows pharynx, esophagus, stomach, small intestine and large intestine ending with rectum to anus part (Figure 3).

Each segment has certain morphological and physiological features, but there is almost a common structure for all parts of GI with muscular walls comprising four different layers: inner mucosa, submucosa, muscularis externa, and the serosa.

Stomach serves the most primarily mixing area and a reservoir that secretes pepsinogen, gastric lipase, hydrochloric acid, and the intrinsic factor. This section of the GI tract is 
normally impermeable for absorption of most materials into the blood except water, ions, alcohol, and certain drugs such as aspirin. It follows small intestine, the major digestive and absorptive site of the GI tract, providing an extended surface area by the circular folds of about $10 \mathrm{~mm}$ height through the microvilli on the absorptive cells of the mucosa. The last part of the GI tract is the large intestine extending from the ileum to the anus with $1.5 \mathrm{~m}$ long and $6.35 \mathrm{~cm}$ in diameter serving mainly the fecal storage and water absorptive roles. It is significant that no enzymes are secreted in the mucosa, and the last stage of digestion is primarily conducted by the resident bacteria [McConnell et al., 2008].

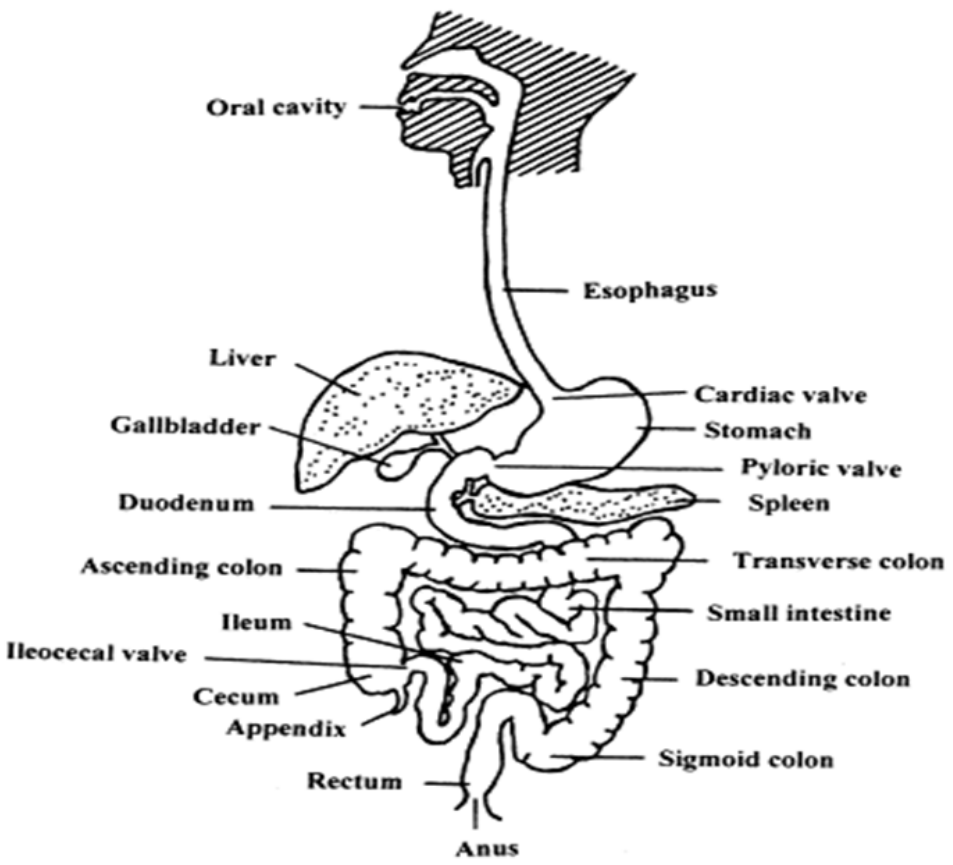

Figure 3. Anatomy of the human gastrointestinal tract [Friend \& Tozer, 1992).

Not surprisingly, these anatomical and physiological parameters of the GI tract remarkably affect the rate and level of drug absorptions and should be assessed. There are several difficulties and rules in designing controlled release systems to be considered for better absorption and enhanced bioavailability of drugs embedded in the orally administered dosage forms. One principal requisite for the successful performance of orally administered drugs is that the drug should have good absorption throughout the GI tract, to certify continuous absorption of the released drug [Davis, 2005]. Regarding the BCS classification of drugs, this could be a major constraint in oral controlled drug delivery systems that not all drugs are evenly absorbed throughout the GI tract. Seeing as, most of the orally administered drugs display region-specific absorption that could be related to differential drug solubility and stability in different regions of the GI tract as a result of changes in environmental $\mathrm{pH}$, degradation by enzymes present in the lumen of the intestine or interaction with endogenous compounds (Table 1). Furthermore, drugs that are substrates 
of certain enzymes in particular regions of the GI tract might have regional variability in their absorption along the GI tract. One should consider this region specific drug absorption concept for designing the ideal drug formulation. It has been widely accepted that about $90 \%$ of all absorption of nutrients takes place in the small intestine, and the rest occurs in the stomach and large intestine, depending on the defining characteristics of GI fluids and membrane surface area at different locations [Davis, 2005]. Consequently, transit time of a pharmaceutical dosage form through the GI tract would determine how long a drug will be in contact with its preferred absorptive region.

\begin{tabular}{|c|c|c|c|c|c|}
\hline Section & $\begin{array}{l}\text { Length } \\
(\mathrm{cm})\end{array}$ & $\begin{array}{l}\text { Diameter } \\
(\mathrm{cm})\end{array}$ & $\mathrm{pH}$ & Major constituents & $\begin{array}{l}\text { Transit } \\
\text { time (h) }\end{array}$ \\
\hline Oral cavity & $15-20$ & 10 & $\begin{array}{l}5.2- \\
6.8\end{array}$ & Amylase, Maltase, Ptyalin, Mucins & Short \\
\hline Esophagus & 25 & 2.5 & $5-6$ & - & Very short \\
\hline Stomach & 20 & 15 & $\begin{array}{c}1.2- \\
3.5\end{array}$ & $\begin{array}{l}\text { Hydrochloric acid, Pepsin, Rennin, } \\
\text { Lipase, Intrinsic factor }\end{array}$ & $0.25-3$ \\
\hline Duodenum & 25 & 5 & $\begin{array}{c}4.6- \\
6.0\end{array}$ & $\begin{array}{l}\text { Bile, Trypsin, Chymotrypsin, Amylase, } \\
\text { Maltase, Lipase, Nuclease, CYP3A4 }\end{array}$ & $1-2$ \\
\hline Jejunum & 300 & 5 & $\begin{array}{c}6.3- \\
7.3\end{array}$ & $\begin{array}{c}\text { Amylase, Maltase, Lactase, Sucrase, } \\
\text { CYP3A5 }\end{array}$ & - \\
\hline Ileum & 300 & $2.5-5$ & 7.6 & $\begin{array}{c}\text { Lipase, Nuclease, Nucleotidase, } \\
\text { Enterokinase }\end{array}$ & $1-10$ \\
\hline Cecum & $10-30$ & 7 & $\begin{array}{c}7.5- \\
8\end{array}$ & - & Short \\
\hline Colon & 150 & 5 & $\begin{array}{c}7.9- \\
8\end{array}$ & - & 4- 20 \\
\hline Rectum & 15- 19 & 2.5 & $\begin{array}{c}7.5- \\
8\end{array}$ & - & Variable \\
\hline
\end{tabular}

Table 1. Anatomical and physiological features of the human GI tract

The usual transit time for a drug formulation or for a nutrient to pass from the stomach to the ileocecal valve (through the small intestine) is around three hours and transit time for colon is much longer up to twenty hours or more. Subsequently, the time a drug will have in its absorption site would be fairly short, more so if the drug is preferentially absorbed in the proximal small intestine rather than throughout the small intestine. Accordingly, a drug that is largely or solely absorbed from the upper GI tract would have variable bioavailability distressed by factors that change GI transit. Moreover, GI transit time of a drug formulation as the most limiting physiological factor in the development of oral drug delivery systems might be altered by the physiological properties of the GI tract too. The patterns of GI transit and gastric emptying depend on whether the person is in a fasted or fed state, and the physical state of the drug delivery system, either a solid or a liquid form [Bode et al., 2004]. 
Gastric emptying of liquids in the fasted state is a function of the volume administered, whereas, indigestible solids are emptied from the stomach as a function of their physical size [Bardonnet et al., 2006; Khobragade et al., 2009].

There also exist several issues affecting motility of the GI tract such as systemic disease, drug therapy and intrinsic GI disorders. Diabetes, idiopathic intestinal muscle disease, Chaga's disease, muscular dystrophy, gastroparesis and etc. are characterized by delayed gastric emptying and a reduction in GI motions. On the contrary, in the case of diarrhea, infectious diseases, thyrotoxicosis and irritable bowel syndrome an increased GI motion is usually detected [McConnell, Fadda et al., 2008]. Even though, increasing the rate of gastric emptying and GI motility increases the rate of drug absorption, for digoxin and riboflavin, increased GI motility is associated with a decrease in the rate of drug absorption. It is of note to be reminiscent of the fact that, a failure in therapeutic efficiency of drugs is inevitable due to the delayed drug absorption issued from altered gastric emptying if the drug has a short biological half-life.

Anticholinergic medications, tricyclic antidepressants, levodopa, and $\beta$-adrenergic agonists are famous groups of medicine that suppress GI motility. Alternatively, drugs that enhance GI motility by increasing contractile force and accelerating intraluminal transit are called prokinetics like metoclopramide, cisapride, tegaserod, and erythromycin (macrolide antibiotic). Other groups of medical preparations (proton pump inhibitors, antacids, histamine receptors type 2 antagonists, etc.) that are used to treat a wide variety of stomach and duodenal diseases associated with hyper-acidity by raising the intragastric $\mathrm{pH}$ would alter the pH-dependent solubility and stability level of a certain kind of drugs administered orally. Most drugs are absorbed via passive diffusion of the nonionized form, so the amount of ionization at the different physiological $\mathrm{pH}$ values encountered in the GI tract would bring about non-uniform drug absorption and bioavailability [McConnell, Fadda et al., 2008].

Although it is not possible to predict accurately the magnitude and clinical relevance of all drug absorption interactions through the GI tract, designing a suitable dosage form that would function independent of the digestive state, clinical condition, or GI motility of the individuals is an imperative fundamental of the drug delivery system dominating these constraints. So the important requisite for the successful performance of oral drug delivery systems is that the drug should have good absorption throughout the GI tract. Since, all the orally controlled-release drug delivery systems would show limited utilization in the GI controlled administration of drugs if the systems cannot remain in the absorption site for the lifetime of the dosage form, establishing a prolonged GI transit time of orally administered drugs appears to be logical.

\section{Prolongation of GI retention}

It is clear from the recent scientific literatures that an increased interest among the academic and industrial research groups still exists in formulating novel dosage forms that are retained in the stomach for a prolonged and predictable period of time. 
The most feasible method for achieving a prolonged and predictable drug delivery in the GI tract is to control the gastric residence time by gastro retentive and sustained release dosage forms that have some beneficial in safety and efficacy over normal release systems. This method of application is especially helpful in delivery of sparingly soluble and insoluble drugs. It is acknowledged that, as the solubility of a drug decreases, the time available for drug dissolution becomes less adequate and so the transit time becomes an important factor affecting drug absorption in drugs with lower solubility. Other drug candidates suitable for gastroretentive drug delivery systems include those drugs that are locally active in the stomach, drugs with narrow absorption window in GI tract, drugs that are unstable in the intestinal or colonic environment, drugs that act locally in the proximal part of GI tract or disturb normal colonic microbes like antibiotics and also drugs that exhibit low solubility at high $\mathrm{pH}$ values. Concerning the pharmacotherapy of the stomach through local drug release of gastroretentive dosage forms, bringing about high levels of drug concentrations at the gastric mucosa (eradication of Helicobacter pylori from the submucosal tissue of the stomach), and treating stomach and duodenal ulcers, gastritis and oesophagitis, the risk of gastric carcinoma would be drastically reduced. In contrast, there are drugs that do not fit in gastroretentive drug delivery systems; Drugs that have very limited acid solubility, drugs that suffer instability in the gastric environment, and drugs intended for selective release in the colon should follow other techniques of drug delivery to reach for their intended site of action. Hence, gastroretentive dosage forms despite providing rather constant drug concentrations in the bloodstream for longer periods of time do not fulfill this benefit with several groups of drugs.

One of the advantages of the sustained release dosage forms is that medication are administered less often than other dosage forms reducing fluctuations of drug concentration in the bloodstream. As a result, patients are not repeatedly subjected to different levels of drug which are less or more than adequate. Nor does the blood chemistry undergo frequent chemical imbalances, which might be risky to the patient's health. Additionally, through gastroretentive dosage forms not only the bioavailability and therapeutic efficacy of drugs are improved but also it may allow for a possible reduction in the dose because of the steady therapeutic levels of drugs. Drugs that have poor solubility in higher $\mathrm{pH}$, absorption windows in stomach, and the ones requiring locall delivery in stomach could be delivered ideally to the site of action by these gastroretentive formulations. On the other hand, drugs that cause irritation to gastric mucosa and the ones meet first-pass metabolism or have stability problems in gastric fluids are not appropriate for these kinds of drug delivery systems.

In brief, gastric retention is a means to enable a delivery strategy that will function irrespective of the digestive state, clinical condition, or GI motility of the individuals with longer drug residence time in the stomach being advantageous in superior drug bioavailabilities and also in certifying local action of some drugs in the upper part of the GI tract. Various approaches that have currently become leading methodologies for increasing the resistance time of a dosage form in the stomach would be highlighted in this section forward. Nevertheless, the early reports on gastroretentive systems have been well-reviewed in pervious literatures, only the more recent development and strategies will be discussed here. 


\subsection{Intragastric floating drug delivery systems}

\subsubsection{Introduction}

Design of floating pharmaceutical dosage forms with a bulk density less than gastric fluid is one of the thriving trends for enhancing drug residence in the stomach. These systems would act independent of the highly variable nature of the gastric emptying process resulting in reduced fluctuations of drug bioavailabilities.

Apart from the commented benefits established by these floating systems, they could also have their limitations given that they require a satisfactory level of fluid in the stomach to float. Likewise, in the fed state a change in body position to supine could have a direct effect on the floating system. In order to design a more systematic and intellectual floating system it is as important as ever to study different aspects of these systems to have a deeper insight to the buoyancy, drug release mechanisms, effectiveness and reliability of these floating systems as an strategy for establishing an efficient gastroretentive drug delivery system [Blanquet et al., 2004].

In this regard, different approaches have been followed to support the buoyancy of dosage forms in the stomach. Based on the mechanism of floatation, two obviously different technologies are employed in development of floating dosage forms, effervescent and noneffervescent systems

\subsubsection{Effervescent systems}

These buoyant systems are usually matrices of swellable polymers along with effervescent components that generate carbon dioxide $\left(\mathrm{CO}_{2}\right)$ entrapped in swollen hydrocolloids of the dosage forms. In these systems floatation is achieved through the incorporating of a gas within the formulation lessoning density of the system and making it float on the gastric fluids [Krogel \& Bodmeier, 1999; Sungthongjeen et al., 2008].

Acid - base reactions have been utilized for decades to produce various pharmaceutical preparations which effervesce as contacting with water. Sources affording the acidity in effervescent reactions are essentially provided by acids, acid anhydrides, and acid salts where organic acids, citric and acetic acids are the most commonly used materials. In contrast, carbonates and bicarbonates in contact with acids are used typically as $\mathrm{CO}_{2}$ generation sources. Carbonates not only play critical role in making the dosage form buoyant but also provide the initial alkaline micro environment for the polymers to gel [Sungthongjeen, Sriamornsak et al., 2008; Patel et al., 2009; Rajab et al., 2010]. These carbon dioxide generating components could be intimately mixed within the matrix to produce a single-layered dosage form or a multi-layered formulation which might contain the gas generating mechanism in one hydrocolloid containing layer and the drug in the other layer formulated for the sustained release effect (Figure 4). The matrices are fabricated so that upon contact with gastric fluid, carbon dioxide is liberated with an upward motion of the dosage form maintaining its buoyancy in the gellified hydrocolloid. Totally, the reaction is due to the $\mathrm{CO}_{2}$ generated by neutralization in the effervescent layer with the diffusion of 
water through the swellable membrane layer. However, there may be a lag time relying on the duration of gas generation reaction that could end in gastric emptying of the dosage form before floatation. More reliable gastric emptying patterns are attained for multi particulate formulations consisting loads of small discrete units as compared with single unit formulations containing one unit suffering from "all or none concept" [Sungthongjeen et al., 2006]. These multi particulate formulations are also better distributed in the GI tract and are less likely to cause local irritation. Recently, much more emphasis is being laid on the development of multi particulate dosage forms rather than single unit systems to their potential benefits like increased bioavailability, reduced risk of systemic toxicity, reduced risk of local irritation and predictable gastric emptying manners.

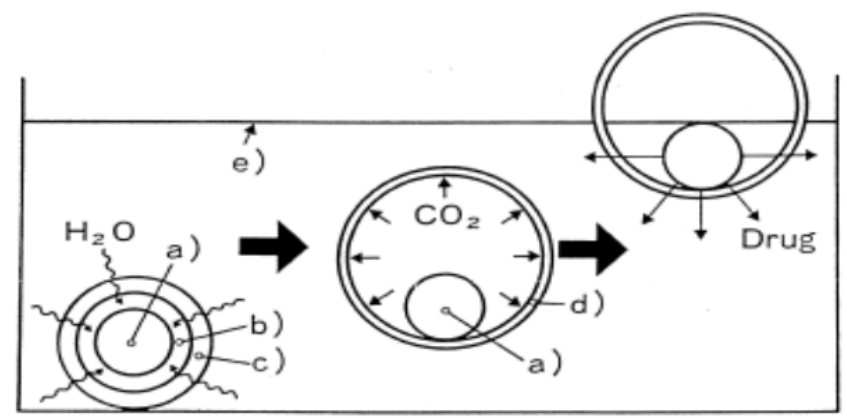

Figure 4. Mechanism of action in effervescent floating drug delivery system.

This view is supported by a variety of papers developing effervescent systems using different polymers and drugs, all agreed in the practicality and feasibility of the approach. In this regard, Pahwa et al. formulated effervescent floating tablets of famotidine with an effective and safe therapy for stomach ulcers in a reduced dose manner [Pahwa et al., 2012]. Hydroxypropyl methylcellulose K15M and hydroxypropyl methylcellulose K100M as gel forming agents along with sodium bicarbonate and citric acid as gas generating agents were used in the research. Concerning the results of the study, it was concluded that the addition of gel-forming polymers, methocel and gas generating agent, sodium bicarbonate along with citric acid were essential to achieve in vitro buoyancy profile. Faster and higher $\mathrm{CO}_{2}$ generation caused by increasing the concentration of effervescent agents resulted in higher swelling of polymeric membrane according to a higher gas pressure [Pahwa, Chhabra et al., 2012]. Additionally, expansion of the hydrated matrices increased the surface area available for dissolution and presence of gas bubbles hindered the diffusion path, decreasing the release constant values. Concisely, in these systems generation of the $\mathrm{CO}_{2}$, entrapped in the matrix is the constant principle rule that has been widely established in studies of this category.

\subsubsection{Non-effervescent systems}

Non-effervescent systems incorporate a high level of one or more gel forming, highly swellable, cellulosic hydrocolloids, poly saccharides or matrics forming polymers into the 
formulations employing no gas forming agents during the procedures. These gel formers, polysaccharides and polymers hydrate in contact with gastric fluids and form a colloidal gel barrier resulting in the floatation of the dosage form. Practical approaches in formulating non-effervescent floating dosage forms are listed below.

\subsubsection{Hydrodynamically Balanced Systems (HBS)}

The HBS systems are developed with gel-forming hydrocolloids forming a hydrated gel layer in the outer exposed surface of the dosage form on contact with gastric fluids imparting buoyancy for a long period of time. Gel-forming or highly swellable cellulose type hydrocolloids such as hydroxypropyl cellulose, hydoxyethyl cellulose, hydroxypropyl methyl cellulose, polysaccharides, matrix forming polymers and the drug that is with gelforming hydrocolloids are homogeneously thoroughly mixed within the HBS formulations [Khattar et al., 1990; Dorozynski et al., 2004]. Hydration of the inner layers brings about surface hydration and a soft gelatinous barrier around the dosage form. This soft gelatinous mass on the surface of the formulation provides a water-impermeable colloid gel barrier on the surface of the tablets. Consequently, the hydrated gel controls the rate of water penetration into the dosage form and the rate of drug release from the HBS. Different varieties of polymers could be utilized in the floating drug delivery systems as well in the HBS. Kumar et al. studied effect of different excipients and polymers on floating behavior and drug release from floating HBS matrices. It was found that the selection of suitable excipients depending on polarity of drug modulates the floatability and drug release profiles where water uptake in the floating matrix increased with the increase in the loading of polar drugs and decreased with non-polar drugs [Kumar et al., 2004]. Elsewhere, a hydrodynamically balanced delivery system of clarithromycin was developed by Nama et al. to prolong gastric residence time with a desired in vitro release profile for the localized action in the stomach, with the intention of Helicobacter pylori mediated peptic ulcer treatment. Different kinds of polymers with various possible concentrations were assessed to establish the optimum formulation with $66.2 \%$ clarithromycin, $12 \%$ HPMC K4M polymer, $8 \%$ sodium bicarbonate offered improved floating lag time less than $3 \mathrm{~min}$ and $12 \mathrm{~h}$ duration of floating [Nama et al., 2008].

In general, use of HBS is desirable which swell to create a gel-like structure after administration and attain a density less than that of gastric fluids where a prolonged drug delivery is required. Not many practical reports were found on the non-effervescent HBS drug formulations as compared to the effervescent systems. As a matter of fact, considering the all or none gastric emptying of HBS dosage forms, development of floating drug delivery system using multiple-unit devices to distribute uniformly within the gastric content and gradually pass through the GI tract still is one of the challenges in this field.

\subsubsection{Porous systems}

Porous materials are emerging day by day as a new category of drug delivery systems due to the several alternative features such as stable uniform porous structure, high surface area, 
and tunable pore sizes with narrow distribution and well defined surface properties. Theses porous carriers have been playing one of the key roles in the pharmaceutical industries including development of novel drug delivery systems such as floating and sustained drug delivery systems in improving the solubility of poorly water soluble drugs [Ahuja \& Pathak, 2009; Sher et al., 2009]. Porous structures such as silica, porous ceramic, ethylene vinyl acetate, polypropylene foam powder and titanium dioxide allow the inclusion of drugs inside a porous compartment possessing a relatively lower density than the gastric juice thus remaining buoyant in the stomach [Streubel et al., 2002]. This approach of flotation is based on the principle of the encapsulation of a drug reservoir inside a microporous compartment with pores along its top and bottom walls. Any other polymer that may be added to the dosage form would moderately cover the pores and entrap air within the system. However, the peripheral walls might get completely sealed to prevent any direct contact of the gastric surface with the drug bringing about delayed release of drugs. Besides, the entrapped air would gradually removed from the formularion in exposure to gastric medium, leading to an extended floating times with a more reproducible and predictable drug release manner. After all, interests and notable surveys have been directed in recent years towards the porous carriers as controlled drug delivery matrices.

A multi particulate floating delivery system, consisting of highly porous carrier material calcium silicate, glipizide as the drug, and eudragit $S$ as the polymer, was developed by Pandya et al. Glipizide as a second-generation sulfonylurea with short biological half-life (3$4 \mathrm{~h}$ ) and the site of the absorption in the stomach was an excellent candidate for development of controlled-release dosage forms that are retained in the stomach increasing the absorption, drug efficiency, along with decrease in dose requirements. In this regard, they evaluated effects of various formulation variables on the internal and external particle morphology, micromeritic properties, in vitro floating behavior, and in vitro drug release. The designed system, showed excellent buoyancy and suitable drug release pattern, possibly being advantageous in terms of increased bioavailability of glipizide over an extended period of time [Pandya et al., 2011].

More recently, Yao et al. developed a simple and rapid method of floatation to prepare a novel kind of inner-porous floating beads using foam solution using poloxamer 188 as foaming agents and alginate as foaming stabilizer. Riboflavin, a water-soluble vitamin was used as a model drug which has a narrow absorption window in the upper part of the intestine and a saturable absorption mechanism. In this method poloxamer 188 was used as an effective amphiphilic surfactant which could lower the water surface tension significantly. In addition, foam solution was formed by stirring in the presence of poloxamer 188, winding microbubbles in the alginate and stabilizing the foam solution. Findings of the study revealed that addition of the non-ionic surfactants poloxamer 188 lead to the formation of a surfactant-polymer complex through interactions between polymer and surfactant contributing in the foamability and foam stability of the formulations. Moreover, higher concentration of the poloxamer 188 increased the foamability and foam stability of the mixed solution. These results were verified through scanning electron microscopy cross- 
section pictures of the beads showing inner-porous with fully bubbled nature of the beads with very thin wall bubbles stacked together. Additionally, gamma scintigraphic images and pharmacokinetic studies in vivo showed that the beads could retain in the stomach for over $6 \mathrm{~h}$ and improved bioavailability of the drug [Yao et al., 2012].

\subsubsection{Alginate beads}

Lately, both natural and synthetic hydrophilic polyionic systems like alginates have been a center of attention for preparation of floating systems. The interest in alginates is chiefly due to their high biocompatibility and nontoxic nature in oral administration that also demonstrate protective effect on the mucous membranes of the upper GI tract. Alginate beads with the structure of spherical gels are taken shaped through dropwise addition of aqueous alginate solution to the aqueous solution containing calcium ions and/or other di and polyvalent cations [Javadzadeh et al., 2010]. The $\mathrm{pH}$ dependent reswelling property of dried alginate beads let them to be administrated as a unique vehicle as the multi unit floating dosage forms in GI tract as early as 1980s [Murata et al., 2000].

In recent years, the amount of literature published on development of these alginate beads providing satisfactory data for a variety of applications has been grown remarkably. In a study, cinnarizine, a piperazine derivative as a Ca channel blocking and anti- histaminic drug suffering from incomplete and variable oral absorption which occurs mainly in the proximal small intestine was formulated as a floating multiple unit dosage form of alginate beads. Ghareeb et al. formulated floating cinnarizine olive oil-entrapped emulsion gel beads by the emulsion-gelation method. They came into conclusion that formulation variables greatly influenced the mean particle size and in vitro drug release characteristics of the prepared beads. Ultimately, the experimental observations suggested cinnarizine loaded alginate beads could potentially be useful in drug delivery systems for making controlled release gastroretentive floating beads of drugs via the ionotropic gelation technique [Ghareeb et al., 2012]. Furthermore, in our previously published paper, we prepared floating beads of metronidazole via the ionotropic gelation method employing gas forming (sodium bicarbonate) and porous (calcium silicate) agents followed by a physicochemical evaluations. It was found that the kind and amount of agents used to make the beads floated, i.e., sodium bicarbonate and calcium silicate, had a profound effect on the beads size, morphology, and floating ability as well as drug release profile [Javadzadeh, Hamedeyazdan et al., 2010]. In general, high compatibility of the alginate beads in achieving a suitable floating dosage form controlling the drug release from the beads with a definite kinetic of release was clear enough to be supported.

Novel prospects for application of floating alginate beads were accomplished by emphasizes on advantages and future potential of probiotic loaded beads in the treatment of GI disorders. As we know, probiotics are live microbial feed supplements that beneficially affect the host by improving its intestinal microbial balance that may undergo antagonistic interactions with pathogenic bacteria. However, significance of probiotics survival in the GI tract, their translocation, colonization and the fate of probiotic derived active components 
indicate a need and scope of packaging them into a suitable delivery system to increase the viability of the probiotics, both outside and inside the body. Singh et al. developed a floating drug delivery system of Lactobacillus acidophilus via orifice ionic gelation method in alginate beads. They evaluated the efficacy of the approach in experimental model of cold restraint stress induced gastric ulcer in terms of ulcer index; hemorrhagic streak length; mucus content and histopathological examinations. According to the authors, the developed formulations not only efficiently protected the entrapped probiotic cells, but also effectively delivered and retained viable bacteria in the stomach [Singh et al., 2012]. The prolonged and continuous release of the probiotic in the gastric mucosa allowed them for an ensured therapeutic efficacy of the developed floating system against ulcers post-induction, thus suggesting an efficient line of treatment.

\subsubsection{Hollow microspheres / microballoons}

One of the renowned approaches in devising multiple unit floating systems are the hollow microspheres (microballoons), spherical empty particles without core that are designed to float on gastric juice [Gholap et al., 2010]. Hollow microspheres incorporating a drug dispersed or dissolved throughout particle matrix have the potential for controlled release of drugs. These microspheres are characteristically prepared by solvent diffusion and evaporation methods where the relative polymer is dissolved in an organic solvent and the drug dissolved or dispersed in the polymer solution is emulsified into an aqueous phase containing suitable additive (surfactants / polymer) to form oil in water emulsion (Figure 5). After removal of the organic solvent, polymer precipitates at the oil/water interface of droplets, forming cavity and thus making them hollow to impart the floating properties. Frequently used polymers in developing hollow microspheres are polycarbonate, chitosan, methocil, polyvinyl acetate, carbopol cellulose acetate, calcium alginate, eudragit, agar and also pectin [Soppimath et al., 2006].

In general, hollow microspheres are believed to be prominent buoyant systems as they provide a multi-unit system with an improved floating property. This view is supported by scores of reports on development of the emulsion solvent diffusion method to form hollow microspheres employing different polymers and drugs to follow a promising drug delivery system floating on the gastric juice. Rosiglitazone hollow microspheres were prepared through modified quasi-emulsion solvent diffusion method by Gangadharappa et al. to improve the oral hypoglycemic agent's bioavailability. The formulated dosage form controlled the drug release, avoiding dose dumping, in an extended floating duration [Gangadharappa et al., 2011]. Elsewhere, Rane et al. prepared hollow microspheres of rosiglitazone were by $\mathrm{O} / \mathrm{W}$ emulsion-solvent diffusion technique using biodegradable anionic acrylic resin as a polymer. They provided evidence that a modification of external aqueous phase with salt $\left(\mathrm{CaCl}_{2}\right.$ and $\left.\mathrm{NaCl}\right)$ improved the drug entrapment efficiency for moderately soluble drug by $45-50 \%$ as a result of salting out effect. Predominantly, the release mechanism for formulations was diffusion controlled and followed the first order kinetics [Rane et al., 2012]. 


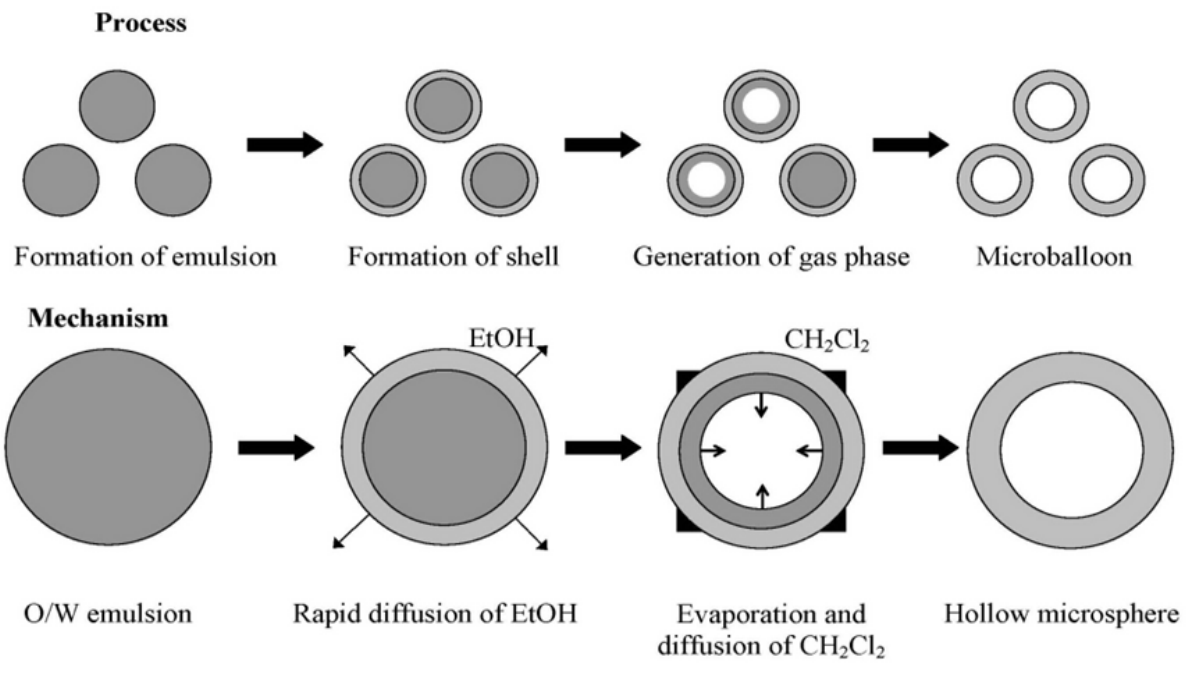

Figure 5. Solvent diffusion and evaporation technique in formation of the hollow inner core microspheres.

\subsubsection{Physicochemical evaluations}

In development phase for floating dosage forms, designing a selection of suitable control principles is of crucial importance. This would be beneficial in preventing the development efforts to costly late stage product failures throughout the manufacture and administration periods too. Besides, health authorities worldwide necessitate accurate adjustment of the physicochemical parameters of the formulation for all individually administered dosage forms in advance to clinical phase [Parikh \& Amin, 2008].

\subsubsection{In vitro buoyancy and drug release properties}

Not surprisingly, insufficient and inconsistent formulation buoyancy, drug dissolution and the subsequent inadequate drug efficacy are some of the routine challenges to be coped with during the development of floating drug delivery systems when they are administrated orally. It is of essential for these kinds of dosage forms to have a satisfactory floating activity, for giving the drug a chance for sufficient dissolution rate, absorption, and a suitable clinical efficacy, as well. Since, different physiological situations may affect the results for buoyancy and dissolution and drug release from pharmaceutical dosage form, in vitro tests for buoyancy and drug release studies are usually carried out in close proximity to the physiological conditions of the human body to lessen the variation derive from altered dissolution medium. The apparatus and procedures of USP are preferred the best to make a better correlation between in vitro and in vivo results of the floating and drug release tests. Generally, the tests are determined in $900 \mathrm{~mL}$ of simulated gastric fluid $(\mathrm{HCl} / \mathrm{NaCl}$ with $0.02 \%$ Tween $80, \mathrm{pH} 1.2)$ maintained at $37^{\circ} \mathrm{C}$ using basket or paddle stirring elements of the USP dissolution apparatus [Mudie et al., 2010]. Besides, the time needed for 
the dosage form to float and duration of the buoyancy are noted as the floating lag-time and flotation time are evaluated as the floating behavior of the formulations.

There have been numerous published reports on diverse challenges of the floating drug delivery systems applying a variety of floating agents to encourage buoyancy of the pharmaceutical dosage forms with a controlled drug release. Gupta at al. prepared floating microspheres of clopidogrel bisulfate using different viscosities of ethyl cellulose and triethyl citrate as a plasticizer using emulsion solvent diffusion technique. It was detected that the drug release from the floating microspheres matrix was completely controlled by the polymer as the polymer proportion in the formulation was increased, a decrease in drug loading, drug release was observed. The floating ability of different formulations was found to be altered according to polymer ratio. Overall, the prepared formulations showed appropriate balance between buoyancy and drug release rate dependent on the amount of formulation variables [Gupta \& Rajpoot, 2012]. Most of the relative papers dealing with the development and optimization of the buoyancy lag time and duration of drug release employed both swellable polymers and gas generating systems to increase the buoyancy and lag times. Several studies in this filed have shown that different factors influence the buoyancy and drug release from a pharmaceutical dosage form and contributing in different patterns of drug release in similar floatation preparation methods.

Accordingly, different factors influence the buoyancy and drug release from a pharmaceutical dosage form. Solubility of the drug in dissolution medium as well as the formulation variables in the dosage form are the dynamic items, contributing distinctively in drug release differences of the floating dosage forms with similar basic floatation preparation methods. It has always been a great challenge to modify the drug release in an expected manner and assess the efficiency of the dosage form in an in vivo environment. Even if the more or less standardized in vitro methods described in the pharmacopeial monographs are used in different studies, the correlation between in vivo and in vitro results must be confirmed from case to case in individuals prior to the clinical application.

\subsubsection{In vivo assessments}

Very early on, in the development phase of drugs a reliable relationship has to be established between in vitro and in vivo test, in order to expose therapeutically relevant discrepancies first between different formulations and later also between drug production batches. This correlation is most likely if the test conditions are in close proximity to the physiological circumstances. Hardly ever, do the in vitro assessments fully counterpart the in vivo results, since the standard USP methods have not been a reliable predictors of in vivo performance of the floating pharmaceutical dosage forms [Kaus et al., 1999]. Apart from the drug release pattern of the dosage form, it is the absorption, distribution, metabolization and excretion influence the in vivo drug concentration at the site of action. In view of the fact that interplay of the pharmacokinetic and pharmacodynamic parameters for a particular drug also has a noteworthy effect on the efficiency of the floating dosage form, in vivo evaluations appear to be requisite. Tracking the in vivo floating behavior and location of dosage form through GI tract providing a broad insight for formulating the 
optimal floating drug delivery system could be established via radiography, gamma scintigraphy, gastroscopy, ultrasonography and magnetic resonance imaging. Considering the majority of the surveys in this case, not only the relevant correlation between in vivo and invitro assessments was confirmed but also effectiveness and reliability of these floating systems as an excellent strategy for controlled delivery of drugs was ascertained [Jain et al., 2006; Ali et al., 2007; Wei \& Zhao, 2008; Guguloth et al., 2011].

\subsubsection{Drug release kinetic for the floating drug delivery systems}

Over the past few decades, the large variety of formulations devoted to floating drug delivery systems with varied physicochemical properties have become manifested which influence the drug release patterns of these formulations. In the same way as the ideal purpose of any drug delivery system is to maintain drug concentration in the blood or in target tissues at a desired value as long as possible, focusing on the drug release profiles to design a more systematic and intellectual floating system is has become even more rational. Accordingly, study of the drug release kinetics is often useful in obtaining one or two physically meaningful parameters which are employed for comparative purposes and relating the release parameter with important parameters such as bioavailability [Wagner, 1969; Barzegar-Jalali et al., 2008; Dash et al., 2010].

There are number of kinetic models, which described the overall release of drug from the dosage forms. Seeing as both qualitative and quantitative changes in a formulation could alter drug release and in vivo performance of the dosage form, developing tools that facilitate drug development by reducing the necessity of bio-studies is always desirable [Arifin et al., 2006; Javadzadeh, Hamedeyazdan et al., 2010]. Referring our former studies on drug release mechanisms from floating drug delivery systems, no a single kinetic model is customary for the floating dosage forms, even if the flotation strategies were the same [Adibkia et al., 2011]. Formulation variables, approaches in establishing formulation buoyancy and the kinetic models in analyzing the drug release data should have chosen parallel to present a suitable model fitting for these systems. In general, evaluating the mechanism behind drug release profile from floating dosage forms is complicated, and requires careful observance of the physicochemical properties of the dosage form.

\subsection{Mucoadhesive gastrointestinal drug delivery systems}

\subsubsection{Introduction}

For years pharmaceutical scientists have been fascinated by the concept of bioadhesion. The term bioadhesion implies attachment of a drug carrier system to a specific biological location like epithelial tissue. This bioadhesion phenomenon is referred to as mucoadhesion if the adhesive attachment is to a mucus coat [Davidovich-Pinhas \& Bianco-Peled, 2010]. Mucoadhesive drug delivery systems are used to localize a delivery device within the lumen to enhance the drug absorption in a site-specific manner since the luminal surface of the GI tract is a richly glycosylated tissue that presents considerable advantages in the use of formulations with mucoadhesive properties. 


\subsubsection{Factors affecting mucoadhesion}

Mucoadhesive characteristics are affected by a factor of both the bioadhesive polymer and the medium in which the polymer will exist in. The mucoadhesive properties of polymers themselves are concerned by diversity of factors such as molecular weight, flexibility, hydrogen bonding capacity, cross-linking density, charge, concentration, and hydration (swelling) of a polymer, which is briefly discussed below [Lahoti et al., 2011].

\subsubsection{Polymer-related factors}

Molecular weight: In general, it has been revealed that the bioadhesive strength of a polymer increases with molecular weights above 100,000.

Flexibility: Bioadhesion could be result of the diffusion of the polymer chains in the interfacial region. Then, containing of a substantial degree of flexibility is essential in order to get the desired entanglement with the mucus. In general, mobility and flexibility of polymers can be related to their viscosities and diffusion coefficients, where in the case of higher flexibility, greater diffusion into the mucus network was seen.

Hydrogen bonding ability: It was found that for occurring of mucoadhesion, polymers must contain functional groups that are able to form hydrogen bonds. It was also showed that flexibility of the polymer is imperative to advance this hydrogen bonding potential.

Cross-linking density: It gives the impressions that with increasing density of cross-linking, diffusion of water into the polymer network take place at a lower rate resulting an inadequate swelling of the polymer and a decreased rate of interpenetration between polymer and mucin.

Charge: Nonionic polymers show a smaller degree of adhesion compared to anionic polymers. It was also shown that some cationic polymers display superior mucoadhesive properties, especially in a neutral or slightly alkaline medium. Furthermore, some cationic polymers such as chitosan that has high molecular weight have shown good adhesive properties.

Concentration: In the lower concentration of the polymer, the number of penetrating polymer chains per unit volume of the mucus is small, and then the interaction between polymer and mucus is unstable. In general, the more concentrated polymer would result in a longer penetrating chain length and better adhesion. However, there is a critical concentration, above which the polymer generates an "unperturbed" situation due to a significantly coiled structure. As a result, the accessibility of the solvent to the polymer decreases, and chain penetration of the polymer is considerably reduced. Therefore, higher concentrations of polymers do not necessarily improve mucoadhesive properties and, in some cases, diminished effect was seen.

Hydration (swelling): For any polymer in order to develop the interpenetration process between polymer and mucin, hydration is required to expand and create a proper "macromolecular mesh" of sufficient size, and also to induce mobility in the polymer chains. 


\subsubsection{Environmental factors}

The mucoadhesion of a polymer not only depends on its molecular properties, but also on the environmental factors adjacent to the polymer $(\mathrm{pH}$, feed condition, and movement of the GI tissues while eating, drinking, or talking). Therefore, an optimum time period for the administration of the dosage form is necessary in order to avoid many of these interfering factors [Lahoti, Shep et al., 2011].

\subsubsection{Polymers used for mucoadhesive drug delivery}

Polymers have played an important role in designing mucoadhesive drug delivery systems. Customarily, in these systems mucoadhesive polymers adhere to the mucin layer on the mucosal epithelium followed by a decrease in drug clearance rate from the GI absorption site, thereby increasing the time available for drug absorption [Rajput et al., 2010]. Polymers used in such system may have natural or synthetic origin. These polymers are classified as:

\subsubsection{Hydrophilic polymers}

These polymers are soluble in water. When put into an aqueous media, start to swell and subsequent dissolution of the matrix is occurred. The polyelectrolytes show superior mucoadhesive property in comparison with neutral polymers. Anionic polyelectrolytes, e.g. poly (acrylic acid) and carboxymethyl cellulose, have been broadly used for preparation of mucoadhesive formulations for their ability to exhibit strong hydrogen bonding with the mucin. Chitosan has been widely used as a cationic polyelectrolyte mucoadhesive polymer developing mucoadhesive property of these systems via electrostatic interactions with the negatively charged mucin chains. Moreover, these ionic polymers might have a drug delivery matrix exhibiting mucoadhesive property by developing ionic complex with the counter-ionic drug molecules. Alternatively, non-ionic polymers, such as poloxamer, hydroxypropyl methyl cellulose, methyl cellulose, poly (vinyl alcohol) and poly (vinyl pyrrolidone), have been used for mucoadhesive properties, as well. The hydrophilic polymers would be used as viscosity modifying/enhancing agents in the development of liquid ocular delivery systems for increasing the bioavailability of active agents by reducing the drainage of the administered formulations since they form viscous solutions when dissolved in water. Accordingly, a mucoadhesive drug delivery system would be established by these polymers when they are directly compressed in the presence of drugs. Polymers that are used frequently in ocular mucoadhesive delivery systems are usual polysaccharides and its derivatives like chitosan, methyl cellulose, hyaluronic acid, hydroxypropyl methylcellulose, hydroxypropyl cellulose, xanthan gum, gellan gum, guar gum, and carrageenan [Roy et al., 2009]. Besides, sustained release of drugs through these hydrophilic mucoadhesive polymers is accomplished in combination of the cationic cellulose derivatives (e.g. cationic hydroxyethyl celluloses) with various anionic polymers.

\subsubsection{Hydrogels}

Three-dimensionally crosslinked polymer chains have the ability to hold water within its porous structure forming hydrogels that are usually characterized with the presence of 
hydrophilic functional groups like hydroxyl, amino and carboxyl groups bringing about the water holding capacity of these hydrogels. However, it is of value to note that with increase in the crosslinking density of hydrogels a decrease in the mucoadhesion would be inevitable. Preparation of the hydrogels by the condensation reaction of poly (acrylic acid) and sucrose pointed out an increase in the mucoadhesive property with the increase in the crosslinking density that was attributed to the rise in the poly (acrylic acid) chain density per unit area. In this regard, Wood and Peppas developed a system in which ethylene glycol chains were grafted on methacrylic acid hydrogels and were functionalized with wheat germ agglutinin. In this system the intestinal residence time of the delivery system was improved by binding of the wheat germ agglutinin with the specific carbohydrate moieties present in the intestinal mucosa. Mucoadhesive hydrogel based formulations not only have beneficial in drug targeting but also they are of use in improving the bioavailability of the poorly water soluble drug. Typically, Muller and Jacobs prepared a nanosuspension of buparvaquone, a poorly water soluble drug, by incorporating it within carbopol and chitosan based hydrogels [Muller \& Jacobs, 2002]. Improved bioavailability of the drug in mucoadhesive delivery systems was determined when compared over the nanosuspension indicating the increased retention time of the delivery system within the GI tract.

\subsubsection{Thiolated polymers}

The mucoadhesive properties of the polymers (e.g. poly (acrylic acid) and chitosan) along with the paracellular uptake of the bioactive agents would be significantly improved through the presence of free thiol groups in polymeric skeleton which could help in the formation of disulphide bonds with that of the cysteine-rich sub-domains present in mucin. Some of the polymers including thiol groups are chitosan-iminothiolane, poly (acrylic acid)-cysteine, poly(acrylic acid)-homocysteine, chitosan-thioglycolic acid, chitosanthioethylamidine, alginate-cysteine, poly(methacrylic acid)-cysteine and sodium carboxymethylcellulose-cysteine [Roy, Pal et al., 2009].

\subsubsection{Lectin-based polymers}

Lectins that are found in both animal and plant kingdom in addition to various microorganisms, are the proteins which have ability to reversibly bind with specific sugar or carbohydrate residues, providing with specific cyto-adhesive property for targeted delivery systems. Lectins extracted from Ulex europaeus I, soybean, peanut and Lens culinarius have demonstrated specific binding to the mucosa. Additionally, wheat germ agglutinin amongst other available lectins has shown limited immunogenic reactions exhibiting potential capacity to bind to the intestinal and alveolar epithelium as the favorable muccoadhesive polymer [Roy, Pal et al., 2009].

\subsubsection{Methods of evaluation}

Mucoadhesive polymers and drug delivery systems can be evaluated by testing their adhesion strength by both in vitro and in vivo tests (Table 2). 


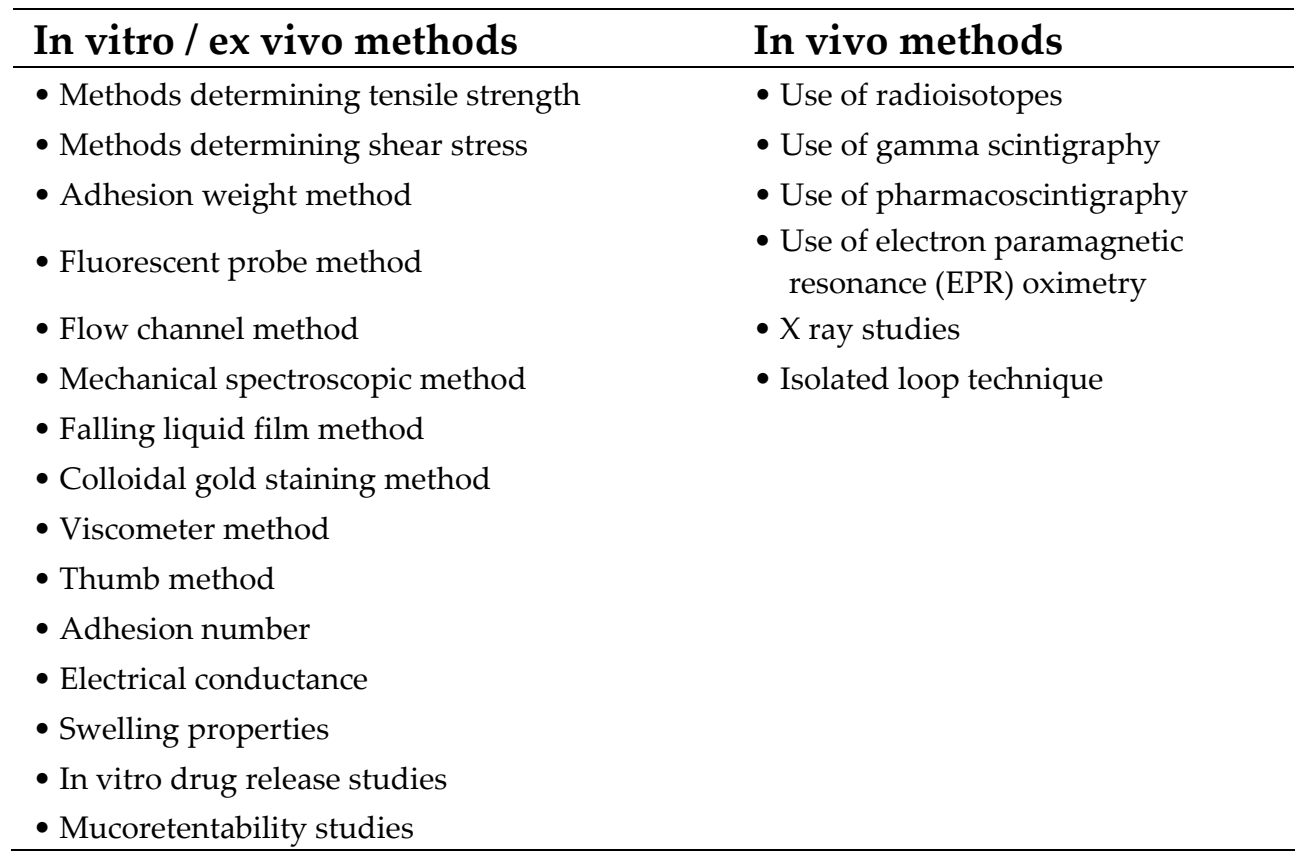

Table 2. Variety of in vitro / in vivo tests for evaluation of the adhesion strength in mucoadhesive sustems

The GI transit time of these dosage forms could be measured by using one of the many radio opaque markers like barium sulphate which is coated to the bioadhesive dosage form so as to assess the GI transit by means of X-ray inspection. Both the distribution and retention can be studied by using of gamma scintigraphy. Using a non invasive technique to determine the transit time of mucoadhesive polymers is also popular and this could be imaged via labeling of the polymer with a gamma emitting nucleotide determining with the help of gamma scintigraphy. Another recent technique is to use magnetic resonance imaging to localize the point of release of thiolated polymers from dosage forms via the use of gadolinium determining by ascertaining the residence time of the fluorescently tagged thiomer on intestinal mucosa of rats after 3 hours [Tangri et al., 2011]). Although, considering the high cost, time consuming and ethical factors, these techniques are less usual common, evaluating the true mucoadhesive potential of the pharmaceutical dosage form is of essential [Shaikh et al., 2011].

Accordingly, there have been several successful attempts in identifying these putative bioadhesive or mucoadhesive materials using in vitro and in vivo tests but success usually has failed in translating to human studies in the stomach and small intestine [Sohrabi et al., 2009; Movassaghian et al., 2011]. It may be due to the lack of correlation between mucosal conditions in the GI tract, and test models that are not in close proximity to the physiological circumstances. This phenomenon reinforces the note that appropriate testing methods are 
required to be developed, with suitable compositions and mechanical forces. Moreover, the continuous production of mucous by the gastric mucosa to replace the mucous that is lost through peristaltic contractions seems to limit the potential of mucoadhesion as a gastroretentive force. On the contrary, colonic mucoadhesion due to the lower mucus turnover and sensitivity to mucus secretory stimulus is much more successful than small intestinal or gastric approaches, due to a thicker mucus layer and lower disruptive colonic motility.

On the whole, it is suggested that this system normalizes the overall variations in drug GI transit time and allows for a more consistent performance of the formulations within and between individuals, improving the overall efficacy of drugs. However, the high turnover rate of gastric mucus and the probable local irritation by these drug formulations has remained challenging in this approach.

\subsection{Conclusion}

Ever since, the pharmaceutical concept of a dosage form seriously manipulate the stability, solubility, bioavailability, and other features of a medicine identifying these potential liabilities allows us to predict, control and avoid any complexities that may arise during pharmacotherapy. Hence, acquiring a clear notion of the assorted characteristics of drug delivery systems will not only allow proficient design of drug formulation, but also an improved in vitro and pre-clinical in vivo behavior of the drug, better in vitro - in vivo correlations, as well as opening new features in administrating drugs via novel drug delivery systems.

\section{Author details}

Yousef Javadzadeh and Sanaz Hamedeyazdan

Biotechnology Research Center and Faculty of Pharmacy, Tabriz University of Medical Sciences, Iran

\section{References}

Adibkia, K.; Hamedeyazdan, S. \& Javadzadeh, Y. (2011). Drug release kinetics and physicochemical characteristics of floating drug delivery systems. Expert Opin Drug Deliv, Vol. 8, No. 7, pp. 891-903, ISSN: 1744-7593.

Ahuja, G. \& Pathak, K. (2009). Porous carriers for controlled/modulated drug delivery. Indian J Pharm Sci, Vol. 71, No. 6, pp. 599-607, ISSN: 1998-3743.

Ali, J.; Arora, S.; Ahuja, A.; Babbar, A. K.; Sharma, R. K.; Khar, R. K. \& Baboota, S. (2007). Formulation and development of hydrodynamically balanced system for metformin: in vitro and in vivo evaluation. Eur J Pharm Biopharm, Vol. 67, No. 1, pp. 196-201, ISSN: 0939-6411. 
Arifin, D. Y.; Lee, L. Y. \& Wang, C. H. (2006). Mathematical modeling and simulation of drug release from microspheres: Implications to drug delivery systems. Adv Drug Deliv Rev, Vol. 58, No. 12-13, pp. 1274-1325, ISSN: 0169-409X.

Asnaashari, S.; Khoei, N. S.; Zarrintan, M. H.; Adibkia, K. \& Javadzadeh, Y. (2011). Preparation and evaluation of novel metronidazole sustained release and floating matrix tablets. Pharm Dev Technol, Vol. 16, No. 4, pp. 400-407, ISSN: 1097-9867.

Badhan, A. C.; Mashru, R. C.; Shah, P. P.; Thakkar, A. R. \& Dobaria, N. B. (2009). Development and Evaluation of Sustained Release Gastroretentive Minimatrices for Effective Treatment of H. pylori Infection. AAPS PharmSciTech, Vol. 10, No. 2, pp. 459467, ISSN: $1530-9932$.

Bardonnet, P. L.; Faivre, V.; Pugh, W. J.; Piffaretti, J. C. \& Falson, F. (2006). Gastroretentive dosage forms: overview and special case of Helicobacter pylori. J Control Release, Vol. 111, No. 1-2, pp. 1-18, ISSN: 0168-3659.

Barzegar-Jalali, M.; Adibkia, K.; Valizadeh, H.; Shadbad, M. R.; Nokhodchi, A.; Omidi, Y.; Mohammadi, G.; Nezhadi, S. H. \& Hasan, M. (2008). Kinetic analysis of drug release from nanoparticles. J Pharm Pharm Sci, Vol. 11, No. 1, pp. 167-177, ISSN: 1482-1826.

Blanquet, S.; Zeijdner, E.; Beyssac, E.; Meunier, J. P.; Denis, S.; Havenaar, R. \& Alric, M. (2004). A dynamic artificial gastrointestinal system for studying the behavior of orally administered drug dosage forms under various physiological conditions. Pharm Res, Vol. 21, No. 4, pp. 585-591, ISSN: 0724-8741.

Bode, S.; Dreyer, M. \& Greisen, G. (2004). Gastric emptying and small intestinal transit time in preterm infants: a scintigraphic method. J Pediatr Gastroenterol Nutr, Vol. 39, No. 4, pp. 378-382, ISSN: 1536-4801.

Dash, S.; Murthy, P. N.; Nath, L. \& Chowdhury, P. (2010). Kinetic modeling on drug release from controlled drug delivery systems. Acta Pol Pharm, Vol. 67, No. 3, pp. 217-223, ISSN: 0001-6837.

Davidovich-Pinhas, M. \& Bianco-Peled, H. (2010). Mucoadhesion: a review of characterization techniques. Expert Opin Drug Deliv, Vol. 7, No. 2, pp. 259-271, ISSN: 1744-7593.

Davis, S. S. (2005). Formulation strategies for absorption windows. Drug Discov Today, Vol. 10, No. 4, pp. 249-257, ISSN: 1359-6446.

Dorozynski, P.; Jachowicz, R.; Kulinowski, P.; Kwiecinski, S.; Szybinski, K.; Skorka, T. \& Jasinski, A. (2004). The macromolecular polymers for the preparation of hydrodynamically balanced systems--methods of evaluation. Drug Dev Ind Pharm, Vol. 30, No. 9, pp. 947-957, ISSN: 0363-9045.

Gangadharappa, H. V.; Biswas, S.; Getyala, A.; Vishal Gupta, N. \& Pramod Kumar, T. M. (2011). Development, In vitro and In vivo Evaluation of Novel Floating Hollow Microspheres of Rosiglitazone Maleate. Der Pharmacia Lettre, Vol. 3, No. 4, pp. 299-316, ISSN: 0975-5071.

Ghareeb, M.; Issa, A. \& Hussein, A. (2012). Prepared and characterized cinnarizine floating oil entrapped calcium alginate beads. IJPSR, Vol. 3, No. 2, pp. 501-508, ISSN: 0975-8232. 
Gholap, S. B.; Banarjee, S. K.; Gaikwad, D. D.; Jadhav, S. L. \& Thorat, R. M. (2010). Hollow microsphere: A Review. International Journal of Pharmaceutical Sciences Review and Research, Vol. 1, pp. 74-79, ISSN: 2231-2781.

Guguloth, M.; Bomma, R. \& Veerabrahma, K. (2011). Development of sustained release floating drug delivery system for norfloxacin: in vitro and in vivo evaluation. PDA J Pharm Sci Technol, Vol. 65, No. 3, pp. 198-206, ISSN: 1948-2124.

Gupta, J. \& Rajpoot, A. (2012). Formulation development and in-vitro evaluation of floating microspheres of clopidogrel bisulfate. IJBTR, Vol. 2, No. 1, pp. 212-218, ISSN: 2249 4871.

Hirtz, J. (1985). The gastrointestinal absorption of drugs in man: a review of current concepts and methods of investigation. Br J Clin Pharmacol, Vol. 19 Suppl 2, pp. 77S-83S, ISSN: 0306-5251.

Jain, S. K.; Agrawal, G. P. \& Jain, N. K. (2006). A novel calcium silicate based microspheres of repaglinide: in vivo investigations. J Control Release, Vol. 113, No. 2, pp. 111-116, ISSN: 0168-3659.

Javadzadeh, Y.; Hamedeyazdan, S.; Adibkia, K.; Kiafar, F.; Zarrintan, M. H. \& BarzegarJalali, M. (2010). Evaluation of drug release kinetics and physico-chemical characteristics of metronidazole floating beads based on calcium silicate and gasforming agents. Pharm Dev Technol, Vol. 15, No. 4, pp. 329-338, ISSN: 1097-9867.

Javadzadeh, Y.; Shokri, J.; Hallaj-Nezhadi, S.; Hamishehkar, H. \& Nokhodchi, A. (2010). Enhancement of percutaneous absorption of finasteride by cosolvents, cosurfactant and surfactants. Pharm Dev Technol, Vol. 15, No. 6, pp. 619-625, ISSN: 1097-9867.

Javadzadeh, Y.; Siahi, M. R.; Asnaashari, S. \& Nokhodchi, A. (2007). Liquisolid technique as a tool for enhancement of poorly water-soluble drugs and evaluation of their physicochemical properties. Acta Pharm, Vol. 57, No. 1, pp. 99-109, ISSN: 1330-0075.

Kaus, L. C.; Gillespie, W. R.; Hussain, A. S. \& Amidon, G. L. (1999). The effect of in vivo dissolution, gastric emptying rate, and intestinal transit time on the peak concentration and area-under-the-curve of drugs with different gastrointestinal permeabilities. Pharm Res, Vol. 16, No. 2, pp. 272-280, ISSN: 0724-8741.

Khattar, D.; Ahuja, A. \& Khar, R. K. (1990). Hydrodynamically balanced systems as sustained release dosage forms for propranolol hydrochloride. Pharmazie, Vol. 45, No. 5, pp. 356-358, ISSN: 0031-7144.

Khobragade, D. S.; Parshuramkar, P. R.; Ujjainkar, A. P.; Mahendra, A. M.; Phapal, S. M. \& Patil, A. T. (2009). Conception and evaluation of sustained release polymeric matrix beads for enhanced gastric retention. Curr Drug Deliv, Vol. 6, No. 3, pp. 249-254, ISSN: 1567-2018.

Klausner, E. A.; Lavy, E.; Friedman, M. \& Hoffman, A. (2003). Expandable gastroretentive dosage forms. J Control Release, Vol. 90, No. 2, pp. 143-162, ISSN: 0168-3659.

Krogel, I. \& Bodmeier, R. (1999). Floating or pulsatile drug delivery systems based on coated effervescent cores. Int J Pharm, Vol. 187, No. 2, pp. 175-184, ISSN: 0378-5173.

Kumar, K. M.; Shah, M. H.; Ketkar, A.; Mahadik, K. R. \& Paradkar, A. (2004). Effect of drug solubility and different excipients on floating behaviour and release from glyceryl 
monooleate matrices. International Journal of Pharmaceutics, Vol. 272, pp. 151-160, ISSN: 2249-3522.

Lahoti, S. S.; Shep, S. G.; Mayee, R. V. \& Toshniwal, S. S. (2011). Mucoadhesive Drug Delivery System: A Review. Indo-Global Journal of Pharmaceutical Sciences, Vol. 1, No. 3, pp. 243-251, ISSN: 2249- 1023.

Martinez, M. N. \& Amidon, G. L. (2002). A mechanistic approach to understanding the factors affecting drug absorption: a review of fundamentals. J Clin Pharmacol, Vol. 42, No. 6, pp. 620-643, ISSN: 0091-2700.

McConnell, E. L.; Fadda, H. M. \& Basit, A. W. (2008). Gut instincts: explorations in intestinal physiology and drug delivery. Int J Pharm, Vol. 364, No. 2, pp. 213-226, ISSN: 0378-5173.

Motlekar, N. A. \& Youan, B. B. (2006). The quest for non-invasive delivery of bioactive macromolecules: a focus on heparins. J Control Release, Vol. 113, No. 2, pp. 91-101, ISSN: 0168-3659.

Movassaghian, S.; Barzegar-Jalali, M.; Alaeddini, M.; Hamedyazdan, S.; Afzalifar, R.; ZakeriMilani, P.; Mohammadi, G. \& Adibkia, K. (2011). Development of amitriptyline buccoadhesive tablets for management of pain in dental procedures. Drug Dev Ind Pharm, Vol. 37, No. 7, pp. 849-854, ISSN: 1520-5762.

Mudie, D. M.; Amidon, G. L. \& Amidon, G. E. (2010). Physiological Parameters for Oral Delivery and in Vitro Testing. Mol Pharm, ISSN: 1543-8392.

Muller, R. H. \& Jacobs, C. (2002). Buparvaquone mucoadhesive nanosuspension: preparation, optimisation and long-term stability. Int J Pharm, Vol. 237, No. 1-2, pp. 151161, ISSN: 0378-5173.

Murata, Y.; Sasaki, N.; Miyamoto, E. \& Kawashima, S. (2000). Use of floating alginate gel beads for stomach-specific drug delivery. Eur J Pharm Biopharm, Vol. 50, No. 2, pp. 221226, ISSN: 0939-6411.

Nama, M.; Gonugunta, C. S. R. \& Reddy Veerareddy, P. (2008). Formulation and Evaluation of Gastroretentive Dosage Forms of Clarithromycin. AAPS PharmSciTech, Vol. 9, No. 1, pp. 231-237, ISSN: 1530-9932.

Pahwa, R.; Chhabra, L.; Lamba, A.; Jindal, S. \& Rathour, A. (2012). Formulation and in-vitro evaluation of effervescent floating tablets of an antiulcer agent. J. Chem. Pharm. Res., Vol. 4, No. 2, pp. 1066-1073, ISSN: 0975-7384.

Pandya, N.; Pandya, M. \& Bhaskar, V. H. (2011). Preparation and in vitro Characterization of Porous Carrier-Based Glipizide Floating Microspheres for Gastric Delivery. J Young Pharm, Vol. 3, No. 2, pp. 97-104, ISSN: 0975-1505.

Parikh, D. C. \& Amin, A. F. (2008). In vitro and in vivo techniques to assess the performance of gastro-retentive drug delivery systems: a review. Expert Opin Drug Deliv, Vol. 5, No. 9, pp. 951-965, ISSN: 1742-5247.

Patel, A.; Modasiya, M.; Shah, D. \& Patel, V. (2009). Development and in vivo floating behavior of verapamil $\mathrm{HCl}$ intragastric floating tablets. AAPS PharmSciTech, Vol. 10, No. 1, pp. 310-315, ISSN: 1530-9932.

Rajab, M.; Jouma, M.; Neubert, R. H. \& Dittgen, M. (2010). Optimization of a metformin effervescent floating tablet containing hydroxypropylmethylcellulose and stearic acid. Pharmazie, Vol. 65, No. 2, pp. 97-101, ISSN: 0031-7144. 
Rajput, G. C.; Majmudar, F. D.; Patel, J. K.; Patel, K. N.; Thakor, R. S.; Patel, B. P. \& Rajgor, N. (2010). Stomach Specific Mucoadhesive Tablets As Controlled Drug Delivery System - A Review Work. International Journal on Pharmaceutical and Biological Research, Vol. 1, No. 1, pp. 30-41, ISSN: 0976- 285X.

Rane, B. R.; Gujarathi, N. A. \& Patel, J. K. (2012). Biodegradable anionic acrylic resin based hollow microspheres of moderately water soluble drug Rosiglitazone Maleate: preparation and in vitro characterization. Drug Dev Ind Pharm, ISSN: 1520-5762.

Riley, S. A.; Sutcliffe, F.; Kim, M.; Kapas, M.; Rowland, M. \& Turnberg, L. A. (1992). The influence of gastrointestinal transit on drug absorption in healthy volunteers. $\mathrm{Br} \mathrm{J} \mathrm{Clin}$ Pharmacol, Vol. 34, No. 1, pp. 32-39, ISSN: 0306-5251.

Roy, S.; Pal, K.; Anis, A.; Pramanik, K. \& Prabhakar, B. (2009). Polymers in Mucoadhesive Drug Delivery System: A Brief Note. Designed monomers and polymers, Vol. 12, pp. 483495, ISSN: 2158-7043.

Shaikh, R.; Raj Singh, T. R.; Garland, M. J.; Woolfson, A. D. \& Donnelly, R. F. (2011). Mucoadhesive drug delivery systems. J Pharm Bioallied Sci, Vol. 3, No. 1, pp. 89-100, ISSN: 0975-7406.

Sher, P.; Ingavle, G.; Ponrathnam, S.; Poddar, P. \& Pawar, A. P. (2009). Modulation and optimization of drug release from uncoated low density porous carrier based delivery system. AAPS PharmSciTech, Vol. 10, No. 2, pp. 547-558, ISSN: 1530-9932.

Singh, P. K.; Deol, P. K. \& Kaur, I. P. (2012). Entrapment of Lactobacillus acidophilus into alginate beads for the effective treatment of cold restraint stress induced gastric ulcer. Food \& Function, Vol. 3, No. 1, pp. 83, ISSN: 2042-6496.

Sohrabi, M.; Soleimani, J.; Roshangar, L.; Vatansever, S.; Arbabi, F.; Khaki, A. A.; Abbasi, M. M.; Dustar, Y. \& Javadzadeh, Y. (2009). The effect of dietary and topical celecoxib on 4nitroquinoline-1-oxide-induced lingual epithelium alternations in rat. J Pak Med Assoc, Vol. 59, No. 11, pp. 769-774, ISSN: 0030-9982.

Soppimath, K. S.; Aminabhavi, T. M.; Agnihotri, S. A.; Mallikarjuna, N. N. \& Kulkarni, P. V. (2006). Effect of coexcipients on drug release and floating property of nifedipine hollow microspheres: A novel gastro retentive drug delivery system. Journal of Applied Polymer Science, Vol. 100, No. 1, pp. 486-494, ISSN: 0021-8995.

Streubel, A.; Siepmann, J. \& Bodmeier, R. (2002). Floating microparticles based on low density foam powder. Int J Pharm, Vol. 241, No. 2, pp. 279-292, ISSN: 0378-5173.

Sungthongjeen, S.; Paeratakul, O.; Limmatvapirat, S. \& Puttipipatkhachorn, S. (2006). Preparation and in vitro evaluation of a multiple-unit floating drug delivery system based on gas formation technique. Int J Pharm, Vol. 324, No. 2, pp. 136-143, ISSN: 03785173 .

Sungthongjeen, S.; Sriamornsak, P. \& Puttipipatkhachorn, S. (2008). Design and evaluation of floating multi-layer coated tablets based on gas formation. Eur J Pharm Biopharm, Vol. 69, No. 1, pp. 255-263, ISSN: 0939-6411.

Tangri, P.; Khurana, S. \& Madhav, N. V. S. (2011). Mucoadhesive drug delivery: mechanism and methods of evaluation. International Journal of Pharma and Bio Sciences, Vol. 2, No. 1, pp. 458-467, ISSN: 0975-6299. 
Wagner, J. G. (1969). Interpretation of percent dissolved-time plots derived from in vitro testing of conventional tablets and capsules. J Pharm Sci, Vol. 58, No. 10, pp. 1253-1257, ISSN: 0022-3549.

Wei, Y. M. \& Zhao, L. (2008). In vitro and in vivo evaluation of ranitidine hydrochloride loaded hollow microspheres in rabbits. Arch Pharm Res, Vol. 31, No. 10, pp. 1369-1377, ISSN: 0253-6269.

Yao, H.; Zhu, J.; Yu, J. \& Zhang, L. (2012). Preparation and evaluation of a novel gastric floating alginate/poloxamer inner-porous beads using foam solution. Int J Pharm, Vol. 422, No. 1-2, pp. 211-219, ISSN: 1873-3476. 